\title{
Os sentidos da crise do militarismo na força pública cearense: notas sobre gestão da hierarquia e das falhas profissionais na PMCE.
}

\author{
Wendell de Freitas Barbosa ${ }^{1}$
}

\section{RESUMO}

Este artigo analisa a Polícia Militar, enfatizando suas práticas e praticantes nos modos relacionais de controle social interno e externo da instituição. Investe-se na compreensão do cotidiano relacional dos policiais militares em suas atividades diárias localizadas nas fronteiras simbólicas do Quartel. $\mathrm{O}$ intento concentra-se em descrever e analisar mecanismos formais informais de produção, administração, resolução e/ou acirramento de conflitos nas relações entre superiores e subalternos, sobretudo aqueles relacionados aos enquadramentos disciplinares, sindicâncias internas realizadas e suas instâncias informais, nas tramas sociais de institucionalização dos "erros" dos internos e suas consequências. A descrição e análise contida aqui é resultado de intensivo e extensivo trabalho de campo etnográfico realizado com policiais militares na Região do Cariri, situada ao Sul do estado do Ceará. O trabalho de campo inclui um período de observação sistemática numa das Companhias de Polícia Militar da Região realizada entre janeiro e setembro de 2015 e, também, a análise de documentos internos produzidos lá, tais como boletins, sindicâncias e fichas de policiais.

Palavras-Chave: militarismo; hierarquia; conflito.

Doutor em Sociologia, Professor Adjunto do curso de Administração Pública da Universidade Federal do Cariri (UFCA).E-mail: wendel.barbosa@ufca.edu.br. 
presente paper aborda os sentidos da crise no militarismo no contexto da gestão da força pública cearense, tendo por base a análise das rotinas e relações hierárquicas na Polícia Militar Cearense. O que está se chamando de "crise do militarismo" envolve tanto questões de ordem externa, como as percepções sociais sobre a instituição, quanto de ordem interna, como as percepções dos policiais militares sobre si mesmos e sobre a corporação da qual são parte. Por um lado, está contextualizada na crise da legitimidade e de confiança da instituição policial no Ceará e no contexto nacional mais amplo - o que está diretamente relacionado ao desprestígio da instituição diante de suas clientelas, panorama observado em pesquisas recentes sobre a confiança da população brasileira nas instituições de segurança pública ${ }^{2}$. Por outro lado, se revela no descontentamento com a profissão experimentado por policiais ao longo da carreira na PMCE. Essas situações envolvem a sensação, por parte dos policiais militares, de falta de reconhecimento de seus superiores hierárquicos e da "sociedade". Em alguns casos, esses elementos da situação crítica da profissão, do ponto de vista dos policiais, estão associados à perda da identificação com a atividade policial e com a cosmologia militar da profissão.

Nesse horizonte de análise, proponho uma interpretação dessa crise a partir de três dimensões: A primeira diz respeito às aproximações e distanciamentos dos valores domésticos do militarismo com valores públicos da democracia e os estilos de compromissos conflitantes que eles

\footnotetext{
$2 \quad$ A mais expressiva dessas pesquisas foi realizada e publicada pelo IPEA em 2012. Segundo os dados apresentados, entre as instituições pesquisadas a Polícia Militar aparece com índices negativos de confiança. Entre os entrevistados, 40, 6\% admite "confiar pouco" na instituição, enquanto $21,4 \% \mathrm{diz}$ "não confiar". Apenas 6,2\% diz "confiar muito" e 31,3\% respondem "confiar" na instituição. Isso acaba por empurrar o grau de confiança nas Polícias Militares para a última posição no comparativo com outros órgãos citados no estudo (Polícia Federal, Polícia Rodoviária Federal e Polícia Civil). Fonte: (IPEA, 2012).
} 
evocam. Essa dimensão é importante, pois envolve situações limites entre obrigações profissionais e formas de autonomia possível desses sujeitos. A segunda dimensão consiste nas demandas políticas de policiais militares. Antes de prosseguir sobre esse ponto especificamente, é preciso descrever a divisão hierárquica entre "oficiais" e "praças" presente na instituição. Tratase de estratos militares descontínuos que separam a hierarquia militar entre a equipe dirigente, o oficialato ( $2^{\circ}$ e $1^{\circ}$ tenentes, capitães, majores, tenente-coronel, coronel e comandante geral), e equipe dirigida, a praça (soldados, cabos, $3^{-}, 2^{\circ}$ e $1^{\circ}$ sargentos); entre os dois, há o estrato das praças especiais (os subtenentes e cadetes). $\mathrm{O}$ ingresso em cada estrato possui requisitos diferentes; atualmente, a posse do título em nível superior é necessária para se candidatar aos quadros do oficialato e realizar o Curso de Formação de Oficiais (CFO); para o ingresso na praça é necessário apenas o ensino médio. O praça que ascender ao topo da carreira, ocupando a graduação de subtenente, só poderá ascender ao oficialato de maneira liminar, por meio dos Cursos de Habilitação de Oficiais (CHO), alcançando o posto máximo de Major - até 2015, o limite era o posto de capitão. Esse posto alcançado por meio do $\mathrm{CHO}$, porém, sempre será um subalterno relativo de um igual formado por meio de um oficial CFO.

Essas demandas políticas têm pautado maior autonomia e liberdade de expressão acerca da sua condição profissional para esses sujeitos, em outras palavras, ações pela amortização das relações de subordinação do militarismo presentes na profissão. Essa situação se tornou mais conhecida com os movimentos paredistas ocorridos no estado (1997 e 2011-2012) e é muito importante para a compreensão desse mundo profissional. A terceira e última dimensão se revela a partir da sensação compartilhada por policiais militares de "injustiça”, "falta de reconhecimento", de "negação de direitos" e diferentes experimentações de situação de sofrimento social nesse mundo profissional. Esses processos envolvem, regularmente, a priorização das 
posições hierárquicas e do capital social com superiores na condução da carreira. Assim, as desigualdades hierárquicas alimentam a instabilidade da concepção de dignidade humana desses sujeitos.

Como recurso para pensar esses aspectos, abordaremos os mecanismos formais e informais de produção, administração, resolução e ou acirramento de conflitos hierárquicos que permeiam a falha profissional no militarismo. Nesse enfoque, são considerados os conflitos hierárquicos presentes na instituição visto sobre diferentes ângulos. Além disso, especial destaque é dado aos enquadramentos disciplinares, morais e penais, presentes nas sindicâncias internas realizadas nas tramas sociais de institucionalização dos "erros” desses profissionais e suas consequências.

O artigo pretende contribuir para elucidar as tramas relacionais no cotidiano profissional da instituição e seus impactos nas trajetórias dos policiais militares. Nesse sentido, apresenta um detalhamento empírico para compreender com mais profundidade as dimensões da organização disciplinar militar. Na descrição e análise da instituição, trata-se de casos que envolvem as relações dos superiores e subordinados, com base em relatos de conflitos interpessoais e profissionais em variadas escalas de gravidade. Esse caminho de problematização dessas relações profissionais tem como fonte principal as memórias de policiais registradas em relatos etnográficos durante a pesquisa de campo.

\section{A gestão da hierarquia militar no trabalho policial: sentidos, normas e conflitos}

As insígnias das graduações e postos militares são costuradas no fardamento dos policiais militares, e tornam públicas as posições hierárquicas no trato cotidiano da organização policial. São símbolos facilmente reconhecidos visualmente, à média e curta distância, independentemente do 
conhecimento da história pregressa do outro policial. Cada graduação e posto tem uma insígnia específica para reconhecimento da sua posição, independentemente da intimidade profissional. Desse modo, mesmo policiais recém-chegados a um batalhão, destacamento ou companhia, podem se reconhecer pelo fardamento. Para detalhar melhor ao leitor, cada graduação será descrita aqui: o Soldado PM expõe uma arma cruzada e uma divisa na cor amarela; o Cabo PM uma arma cruzada e duas divisas na cor amarela; $3^{\mathbf{0}}$ Sargento PM uma arma cruzada e três divisas na cor amarela; $2^{\underline{0}}$ Sargento PM uma arma cruzada e quatro divisas; 1- Sargento PM uma arma cruzada e cinco divisas na cor amarela. No círculo das praças especiais, o Subtenente PM ostenta na platina um triângulo vazio na cor amarela e o Cadete PM uma estrela amarela com cinco pontas. Passando para o círculo dos oficiais em ascendência hierárquica, o $2^{\text {o }}$ Tenente PM carrega na platina uma estrela prateada simples(cinco pontas); $\mathbf{1}^{\mathbf{0}}$ tenente duas estrelas prateadas simples; Capitão PM três estrelas prateadas simples; Major PM uma estrela dourada composta e duas estrelas prateadas simples; o TenenteCoronel PM duas estrelas douradas compostas e uma estrela prateada simples; Coronel PM três estrelas douradas compostas.

Os praças, até a graduação de sargento, possuem divisas representadas por dois vértices que apontam para cima $^{3}$, costuradas nas mangas da camisa. $\mathrm{O}$ simbolismo das divisas enfatiza a força física e simbólica da instituição, características dessas graduações do círculo hierárquico da praça, os policiais da linha de frente para a aplicação da força. Os subtenentes e oficiais carregam as platinas, presilhas fixadas nas ombreiras do fardamento, a praça especial subtenente é identificada por um triângulo equilátero

3 As divisas parecem representar, além disso, o símbolo da fertilidade masculina. Um falo apontado para cima. Alguns interlocutores metaforizam a hierarquia com base nas divisas, quem tem mais, manda mais, utilizando a referência do sexo masculino para aludir às relações de poder no círculo da praça. 
vazado. Os oficiais carregam um código de diferenciação especial, suas insígnias são representadas por “estrelas”. A posição em que são carregadas, acima dos ombros, alude à "inteligência" relativa da potencialidade dirigente e administrativa. As estrelas simbolizam o cosmos, associadas na mitologia militar, as divindades onipotentes e oniscientes. Essas virtualidades hierarquizam especialidades profissionais no simbolismo da farda.

A hierarquia é um princípio assegurado nos códigos morais, penais e disciplinares da PMCE. Se expressa, por vezes, como uma linha divisória, distintiva e virtualizada nas linhas que desenham o fardamento e costuram as "divisas" e "platinas". As fardas mudaram ao longo do tempo e, também, a regulamentação do local de exposição da insígnia. Em tentativas recentes de amortizar as hierarquias da instituição, foram realizadas alterações no uso do fardamento sobre a questão da exposição das insígnias ${ }^{4}$. No período recente da instituição, por um curto lapso de tempo, praças e oficiais puderam ostentar suas insígnias nas ombreiras do fardamento. A regulamentação do comando da instituição vigente no ano de 2015 retornou a exposição para o formato tradicional: as insígnias dos oficiais permaneceram nas ombreiras, já a dos praças voltaram novamente para as mangas da camisa 5 .

Para adentrar aos sentidos que essas dimensões normativas ganham no cotidiano das relações da instituição, tomemos, por exemplo, a visão de policiais militares do círculo da praça sobre essa questão. Em certa ocasião

\footnotetext{
$4 \quad$ No ano de 2015 a cor das fardas da polícia militar, da maioria das modalidades de policiamento, foi padronizada no tom azul claro, exceção feita para o RAIO, o CHOQUE, GATE e a CPMA, programas que têm em seu fardamento cores e estéticas distintas dos demais, por serem elites militares e grupos táticos.

$5 \quad$ Disponível em: $\quad<$ http://www.pm.ce.gov.br/index.php/legislacao-militarestadual/category/2- downloads?download=7\%3Aregulamento-de uniformes $>>$
} 
do trabalho de campo, eu estava, junto a um grupo de praças em serviço no quartel, conversando sobre o assunto. Embora reticente sobre os possíveis motivos dessa mudança, o Cb. PM Francisco expressou-se assim:

\footnotetext{
meu filho[referindo-se a mim], você ainda vai descobrir, mas quem manda aqui na polícia são os oficiais. Veja meu caso, eu entrei no mesmo período do Major Paulo, eu como soldado e ele como tenente. Enquanto ele já teve três promoções, eu obtive apenas uma, veja só! Quando a gente usava nos ombros a divisa, causava uma ciumeira danada. Tinha $1^{\mathrm{o}}$ sargento que parecia um coronel três estrelas de longe. Lembra-se do sargento Leandro?(dirigindo-se a outro companheiro). Eles não gostavam de se confundir com a gente, não, e voltou a ser como antes. [Relato do Cabo PM Francisco, informação verbal, maio de 2015.]
}

Essa interpretação foi muito rica para adentrar nesse universo relacional, em que os fardamentos vestiam não só os corpos, mas também costuravam as relações de poder entre oficiais e praças. $\mathrm{O}$ impacto da hierarquia militar no modo de vida dos policiais militares é um tema profícuo para pensar a tensão entre o campo de obrigações e as autonomias profissionais dos policiais militares. Para compreender esse mundo profissional, mais do que analisar como e por que alguém é autorizado a controlar a conduta de outras pessoas, influenciando suas trajetórias na corporação, é preciso esmiuçar essas relações como fazendo parte de uma configuração social mais ampla. Trata-se da fabricação social de fronteiras entre o mundo militar e o mundo civil, implicadas diretamente nas percepções desses profissionais. Para fazer isso, é necessário compreender o conteúdo cultural e o significado moral da subordinação de uma perspectiva mais ampla, para depois trazê-la ao chão das relações detalhadas e analisadas. Ainda no início do Século XX, Georg Simmel dizia que as relações sociais de subordinação na modernidade não suprimiam totalmente a liberdade humana, a não ser em casos de coação física extremas. Ao invés disso, a relação de subalternidade estabelece um "preço", que o subordinado está disposto a pagar, em troca de um controle exterior sobre 
essa liberdade (SIMMEL, 1977, p. 149).

Simmel também explora o modo como as instituições sociais dotadas de uma "força supra-individual” - como é o caso da polícia - conferem a uma "personalidade individual” um prestígio, uma dignidade, um poder de decisão inapelável que, até então, não havia surgido em sua individualidade própria. Essa é a leitura que o autor faz de como certos processos de pertencimento conferem a certas pessoas a condição de "autoridade", mas estabelecem por isso um preço, não só no sentido monetário, mas também no sentido moral, em termos de obrigação social. A corporação da polícia militar, por exemplo, confere aos seus profissionais uma matriz da autoridade que é o "prestígio", mas também designam para esses sujeitos a missão "sagrada" que ela possui. Essa "autoridade" social é concedida ao preço de que esta seja regulamentada pelas suas normas e fundamentada nas tradições hierárquicas em que a instituição se assenta. Esse processo, que poderíamos definir como desigual distribuição da dignidade e autoridade entre os policiais, se dá por meio do reconhecimento de determinados valores sociais (hierarquia, disciplina, verdade real, camaradagem etc.) e qualidades humanas (inteligência, força, destreza etc.), por exemplo.

As formas de controle social presentes no modo de vida militar exercem um duplo vínculo. Por um lado, a vigilância é o modo de administrar a eventual falha dos membros da instituição, um dispositivo fundamental para coibir abusos de poder ou o desvio criminal e disciplinar do policial. Por outro, a vigilância também permite construir uma experiência significativa na profissão, ao ensinar aos policiais o modo como certas situações podem tornar o policial uma vítima potencial do desvio de outro policial, seja ele subordinado, equivalente ou superior; eles são levados a pensar de maneira positiva as maneiras corretas de desempenhar suas atividades e se inspirar nesse horizonte. 


\section{Modos institucionais da conversão da falha profissional em punição no modo de vida militar}

Além das corregedorias que investigam denúncias contra ilegalidade cometidas por policiais militares, na própria estrutura administrativa da PM existem meios de investigação que produzem documentos sobre a conduta irregular de policiais, quando se torna conhecida pelos superiores. Ante essa ocasião, a averiguação torna- se uma obrigação disciplinar, na qual o superior deve comandar o processo de averiguação do possível desvio funcional do subordinado. Inicia-se assim: “o comandante designa um oficial para a sindicância de um praça do POG, acusado de abuso de autoridade" (trecho de um dos boletins circulados durante o ano de 2015). O oficial nomeado verifica a ocorrência de transgressões disciplinares, visitando as vítimas e fazendo diligências sobre os fatos, constatando ou não a materialidade da acusação. A indicação do oficial que realizará as investigações leva em consideração o efetivo formado pelo Curso de Habilitação de Oficiais, ex-praças em condição de oficiais de "segunda linha” 6 . Um oficial do $\mathrm{CHO}$ com a mesma pontuação que um CFO, será sempre mais moderno em relação a esse último. Embora os códigos administrativos não recortem especificamente essa situação, as tradições hierárquicas ensinam esse lugar de atuação para os ex-praças habilitados a tornarem-se oficiais por meio do $\mathrm{CHO}^{7}$. Em grande parte desses procedimentos, eles atuam nas investigações chefiadas pelo comandante da

\footnotetext{
6 Até a legislação vigente no ano de 2015 os oficiais $\mathrm{CHO}$ só poderiam alcançar o posto máximo de capitães. Com a nova lei sancionada a partir desse ano, criou-se a vaga de major para estes policiais.

7 Durante todo o trabalho de campo presenciei muitos relatos de desproporção do tratamento entre desvios disciplinares e penais do oficialato e da praça. Mesmo oficiais notadamente cometedores de crimes militares no passado da região, dificilmente sofreram expulsão, a punição extrema. Já entre os praças, a expulsão é muito mais recorrente para crimes militares graves.
} 
companhia ou do batalhão.

É através de uma denúncia de alguém além-caserna, informando uma prática cometida por um policial militar, que se inicia um processo de sindicância para "apurar os fatos e as pessoas envolvidas", realizado a partir da própria PMCE, não por um órgão de segurança pública externa. É o modo pelo qual o a agente da ordem e da lei passa a ser também acusado de violar os códigos disciplinar e penal da caserna ou, ainda, a legislação criminal civil. Nas sindicâncias realizadas naquele batalhão durante o ano de 2015, nenhuma delas eram contra oficiais. Isso pode reforçar dois aspectos a título de hipótese: 1. O fato de o efetivo de oficiais ser bem menor em comparação aos de praça; 2. Os oficiais se protegem de sindicâncias e recorrem a outras formas de investigação menos intensas. Essas não são hipóteses exclusivas, mas complementares. A justificativa dada para isso pelos policiais que já atuaram na produção das sindicâncias, sendo um deles o tenente Flávio $\mathrm{CHO}$, é que os oficiais costumam se preservar desses processos, usando de outros meios informais de controle sem a produção de uma documentação interna.

A análise das sindicâncias foi muito rica para explorar as ferramentas simbólicas usadas para coibir práticas ilegais cometidas pelos policiais militares. As sindicâncias recaíam contra policiais acusados que eram ao fim absolvidos, por falta de materialidade, ou considerados culpados por seus crimes e desvios disciplinares. Ao fim dos processos, o delito era classificado, o inquérito era encaminhado à justiça militar, contendo os testemunhos, a documentação das provas, as conclusões do sindicante e o parecer do comando local, aplicando punições para os subordinados.

O processo conta com a participação de sindicante, sindicado, advogados de defesa, escrivães e é regulamentado pela Controladoria Geral de Disciplina. O processo de defesa do acusado é tocado pelas associações locais ou 
advogados particulares do PM acusado, dependendo de sua filiação nas associações ou opção pessoal. Em conversa com o presidente de uma dessas associações, ele confidenciou que a principal estratégia nessas ocasiões é desarmar o caráter hierárquico que essas investigações assumem, destinando o subalterno ao peso punitivo dos códigos, sem presunção de inocência ou reconhecimento pelo que ele chama de "bons serviços prestados". Ao invés de categorizar o policial como alguém que merece ser punido por suas falhas, a associação orienta os advogados a explorar a história do policial na instituição, expondo detalhes de suas fichas, mencionando seu comportamento, suas notas, seus elogios, "seus bons serviços prestados" para reconstruir seu valor profissional. Além disso, os processos mostram regularmente testemunhos de defesa prestados por amigos, familiares, colegas de profissão e "civis" já assistidos pelos policiais. Dependendo da gravidade do delito e da "materialidade" da denunciação, a penalidade poderá ser mais severa ou mais branda.

A sindicância realizada contra o soldado Fagner em 2015 objetivava “averiguar a prática de crime militar pelo soldado”. Era uma situação muito grave, em que ele era acusado de transgressão disciplinar e de violar o código penal civil. O caso tornou-se alvo de uma sindicância após o soldado ser vítima de lesão corporal, o que deu publicidade ao ocorrido. Ele sofreu um disparo de arma de fogo em sua perna direita. Um amigo particular do policial, agente de trânsito, foi o seu algoz, após um grave conflito. O policial visitava seu amigo e levou consigo uma lanterna que causava choques - ele tinha intenção de aplicar choques no corpo de Raimundo, com quem tinha amizade pessoal havia bastante tempo. A partir daí as versões do sindicado, do autor do disparo e das testemunhas confundem o que de fato aconteceu. Na peça, o policial era acusado de violar o artigo 129 do código penal brasileiro, "Ofender a integridade corporal ou a saúde de outrem”. Além disso, o soldado, de acordo com o sindicante, cometera 
transgressão disciplinar violando "valores fundamentais" e "deveres consubstanciados" pela ética militar. Entre os valores violados citados no processo estavam “a lealdade”, “a verdade real”, “a honra” e "a dignidade humana”. Os deveres não cumpridos pelo praça eram: "procurar manter boas relações com outras categorias profissionais, conhecendo e respeitando-lhes os limites de competência, mas elevando o conceito e os padrões da própria profissão, zelando por sua competência e autoridade", "zelar pelo bom nome da Instituição Militar e de seus componentes, aceitando seus valores e cumprindo seus deveres éticos e legais" e "proceder de maneira ilibada na vida pública e particular".

De acordo com agente do DEMUTRAN Raimundo, ao perceber a tentativa do soldado em aplicar os choques com a lanterna, entrou em disputa corporal. Durante o confronto, ele recebeu vários choques no corpo, caindo ao chão e sacando a sua arma de fogo, que disparou acidentalmente contra o policial. $\mathrm{O}$ agente justificou o acidente alegando uma amizade de mais de 10 anos com o policial. Após o disparo, ele e sua esposa acionaram o socorro para o soldado. Já Fagner, reconhecia a posse da lanterna, confirmando o testemunho do amigo em parte, exceto no que dizia respeito ao disparo acidental do revólver. Na versão do policial, após “a humilhação” diante da esposa, o agente sacou a arma, apontou e realizou o disparo.

Diante da gravidade das consequências de suas atitudes, embora não estivesse formalizada nenhuma denúncia por parte da vítima contra o policial, alegando a violação do código penal, a sindicância formalizou esse processo, acrescentando também outras violações disciplinares do solado. Pesava no histórico da instituição ser o soldado, na visão dos comandantes, um "maceteiro", alguém que se usava indevidamente de licenças de tratamento de saúde para não trabalhar - percepção que ganhou ainda mais força pela "má conduta do militar". Fagner, como outros colegas, adquiriu hérnia de disco em decorrência da própria profissão e estava afastado do 
serviço havia aproximadamente seis meses. Embora o atestado médico garantisse a legitimidade do afastamento, ele relatava a colegas mais próximos usar a LTS para conseguir concluir o curso de graduação em uma IES particular da região. Fato que era conhecido pelos oficiais que acompanhavam seu afastamento. Seu histórico de soldado "enrolão" o perseguia e ocasionou três transferências do policial por atos administrativos de superiores.

Antes mesmo da sindicância, Fagner já tinha chamado para si a atenção dos superiores que acompanhavam sua situação de perto, planejando contestar a sua licença e devolvê-lo à atividade policial. Policial militar desde 2003, seu comportamento na instituição também foi levado em consideração, Fagner ingressou na atividade profissional em 2003 com "bom" comportamento, progrediu no ano de 2008 para "ótimo", e no ano de 2013 alcançou a classificação "excelente". O policial não tinha histórico de transgressões disciplinares em pouco mais de 10 anos de serviço, fato que pesou a seu favor. Fagner possuía inúmeros elogios por "bons serviços prestados", de acordo com as sua ficha: 2004(1) 2005(1), 2007(2), 2008(2), 2009(2), 2010(1), 2013(1), fato bastante explorado pela defesa para desagravar suas falhas morais. Dois desses elogios eram referentes à apreensões de arma de fogo e operações contra o tráfico na região, das quais o soldado participaram oportunidades e nas quais cumpriu com seu "dever constitucional”, demonstrando "abnegação" e "enobrecendo a causa policial militar". Os demais elogios são ordens do comandante sem uma causa específica, o comandante local faz esse tipo de elogio coletivo uma ou duas vezes por ano, sem motivo aparente, mas seguindo padrões temporais e de pertencimento à instituição ${ }^{8}$.

8 Exemplos desse tipo de elogio são: 1. O comandante Major Fulano decide elogiar todos os policiais que ingressaram naquela companhia após o ano de 2004. 2. [...] Decide 
Este caso é exemplar, pois demonstra como um réu primário teve esquadrinhada sua primeira falha profissional. O primeiro registro de uma punição decorrente da violação de regimentos disciplinares do militarismo e até mesmo violação do código penal civil. Todo o contexto do evento expressa um modo de choque entre ambas as instâncias, civil e militar; tanto pelo acontecimento durante seu afastamento da caserna, quanto por contar com a participação decisiva de actantes civis. A publicidade do acontecimento levou à apuração dos fatos pela caserna, gerando efeitos punitivos oficialmente atribuídos na esfera militar e civil. Fosse Fagner oriundo de outra área de atuação, provavelmente não responderia criminalmente, uma vez que sua vítima não procurou a justiça para acusá-lo formalmente.

A principal estratégia do soldado para minimizar os efeitos punitivos foi alegar que o "o choque não foi intencional, ocorrendo durante uma disputa corporal", enfatizando que tudo não passava de uma brincadeira entre amigos, até o rumo imprevisto que o conflito tomou: a lesão corporal. Raimundo, por sua vez, foi a acusado na justiça comum por lesão corporal, alegando ter sido o disparo acidental, embora fosse culpado pela posse ilegal de arma de fogo.

A preocupação com a visão que os superiores têm sobre a conduta dos subordinados é recorrente entre os policiais. Controlar a reputação moral é um modo de blindar-se contra investidas de vigilância mais sistemáticas por parte dos superiores. Muitos policiais, sabendo de muitos relatos

elogiar todos os policiais escalados no serviço interno; 3. [...] Decide elogiar todos os policiais escalados em certa modalidade de patrulhamento. São ordens que equilibram o comportamento médio dos subordinados. Desse modo,"O elogio coletivo visa a reconhecer e a ressaltar um grupo de policiais militares ou fração de tropa ao cumprir destacadamente uma determinada missão."(Trecho extraído do código disciplinar da PMCE). 
compartilhados entre seus pares, esforçam-se para não terem atestado em sua ficha um baixo comportamento. É nesse sentido que "la catégorie de « faute professionnelle» traverse pourtant toutes ces situations où elle joue, pour certains protagonistes, le rôle d'un résumé susceptible ·d'appuyer un jugement moral" (CHATEAURAYNAUD, 1991 p. 20). A qualidade do comportamento, bem como o histórico disciplinar dos policiais os torna mais ou menos suscetíveis a julgamentos morais e disciplinares. É o modo como os usos discricionários dos regimentos militares e códigos penais são associados a certo tipo de práticas e pessoas no interior da instituição. Esta condição revela formas "de la justification des conduites et du règlement des disputes sur les lieux de travail ou devant les tribunaux"(IBIDEM, ibidem P. 21).

Os policiais militares possuem fichas com o histórico desde o ingresso na corporação; trata-se da documentação biográfica disciplinar e moral dos homens e mulheres da força pública brasileira. Ao final do curso de formação, eles são classificados com "bom" comportamento, essa é a condição de ingresso na praça. Conforme são designados para atuarem no serviço de rua ou interno, eles passam a interagir mais decisivamente com superiores que são obrigados pelos códigos a investigar, classificar e punir e desvios disciplinares, crimes militares e civis cometidos por seus subordinados. Se o policial comete uma transgressão e o erro é institucionalmente rotulado, ele sofrerá uma punição que terá um prazo até sua expiração, ou cancelamento, dependendo da gravidade. As "advertências" verbal e escrita são canceladas após dois anos; a "repreensão" dura três anos até sua expiração; a "permanência disciplinar", antes da legislação atual tratada como "detenção", sete anos; e, por fim, a custódia disciplinar ou, anteriormente, "prisão administrativa”, que expira no prazo de dez anos.

Cada punição poderá ocasionar uma regressão no comportamento. A ordem 
decrescente do comportamento é regulada pelo código disciplinar. "Excelente" - quando, no período de 10 (dez) anos, não lhe tenha sido aplicada qualquer sanção disciplinar, mesmo por falta leve; “Ótimo” quando, no período de 5 (cinco) anos, lhe tenham sido aplicadas até 2 (duas) repreensões; "Bom" - quando, no período de 2 (dois) anos, lhe tenham sido aplicadas até 2 (duas) permanências disciplinares; "Regular" quando, no período de 1 (um) ano, lhe tenham sido aplicadas até 2 (duas) permanências disciplinares ou 1 (uma) custódia disciplinar; "Mau" - quando, no período de 1 (um) ano, lhe tenham sido aplicadas mais de 2 (duas) permanências disciplinares ou mais de 1 (uma) custódia disciplinar.

Essa submissão continua ao julgamento moral dos pares, no cotidiano da caserna escolhe alvos preferenciais, uma vez que seria muito difícil aplicar toda a energia do oficialato para controlar todos os homens e mulheres a eles subordinados. Um bom relato para expressar a construção de subordinados em evidência aconteceu com o soldado Flávio. Ele e outros colegas tinham um relacionamento muito ruim com um sargento muito próximo dos oficiais da região. Ele se dizia vítima de uma "cruzetagem" do Sgt. PM Odílio. O "graduado", segundo ele, não perdia a oportunidade de falar mal do soldado publicamente, inclusive aproveitando-se da presença de oficiais. Segundo Flavio, Odílio sempre quando escalado de serviço com o subordinado, dizia ironicamente que ele era seu "peixe", uma expressão utilizada geralmente para enfatizar relações de camaradagem e poder, mas empregada ironicamente pelo sargento, reforçando a péssima relação entre ambos.

Ocorreu do Sd. PM Flávio se "enrolar" gradualmente, fato iniciado, supostamente, por “cruzetagens" sistemáticas do sargento, alegando imprudência e imperícia durante os serviços. Uma rede de atenção foi voltada para o soldado e não demorou a novas falhas tornarem-se erros publicamente rotulados nas relações da caserna. O estopim foi um acidente 
de trânsito envolvendo a viatura dirigida pelo soldado em companhia do sargento, colidindo contra uma moto, porém sem consequências graves para os policiais e para a vítima. Os reparos da viatura e da moto foram devidamente descontados nos rendimentos do policial. Foi realizado um inquérito técnico pelos superiores para atestarem o prejuízo e efetivarem a cobrança. Pouco tempo depois, o policial foi notificado com sua transferência para outra cidade da região, consequência que atribuía à mácula em torno de seu nome construída pela cruzeta do graduado. $\mathrm{O}$ acontecimento, porém, não foi isolado das relações sociais da corporação e seu desenrolar construiu uma série de identificações com outros iguais da praça, como o Soldado Alan, que se percebia como uma vítima em potencial dessas práticas.

O que Alan nem Flavio sabiam é que o sargento respondia na justiça militar por constantes atrasos no serviço. A pesquisa documental realizada nos boletins e sindicâncias do batalhão permitiu conhecer o histórico disciplinar e penal de alguns dos policiais interlocutores da pesquisa. Observou-se nos boletins duas convocações da justiça militar para o Sargento. O processo contra o policial apontava cerca de dez atrasos registrados no "caderno do adjunto" e confirmados pelo comandante local. A sindicância confirmou os fatos e encaminhou o inquérito à Justiça Militar, que passou a julgar o caso. Por mais graduado que fosse, em relação ao soldado, o sargento também estava suscetível à rotulação institucional de sua falibilidade e sofria as consequências de seus atos, por ações sancionadas por seus superiores, sem contudo resultar na sua transferência, diferentemente do soldado. Por mais atingida que a sua reputação moral fosse com esse processo, o graduado estava na condição de influenciar o destino de seus subordinados.

O curioso dessa situação é o modo como as obrigações são incorporadas nas relações hierárquicas e a “camaradagem” é suspensa pela “cruzetagem”. Mostrando-se um sargento preocupado com a disciplina dos seus 
subordinados, comunicando aos oficiais suas falhas e prezando pela "causa policial militar", o sargento poderia recuperar o prestígio desgastado com seus superiores, abrindo caminho parra o seu subordinado se "enrolar". Tudo se passa como se a estratégia de cruzetagem fosse o modo de transferir redes de vigilância para outros policiais, na tentativa de livrar a própria pele, como no caso do soldado. Não é uma atitude bem vista pelos companheiros de farda, mas é uma estratégia bem sucedida com base em seus objetivos, sendo embasada juridicamente. A cruzetagem é um modo de manobrar as implicações da falha profissional, explorando as falhas profissionais de outros, para restaurar ou acumular prestígio profissional com os superiores. Desse modo, muitos interlocutores associam a figura humana do Sgt. PM Odílio à condição de “T.A.jotinha”, uma expressão êmica para categorizar policiais que mantém "relações promíscuas", violando os cortes interacionais hierárquicos para dedurar companheiros. Essa classificação rotula a pessoa como um "entregão" contumaz das falhas dos colegas, cujo intuito é blindar-se de uma vigilância mais intensa sobre suas práticas profissionais e pessoais. Na perspectiva do cruzeta, por outro lado, suas práticas são embasadas nos próprios códigos que regulam a conduta dos policiais e tornam uma obrigação disciplinar denunciar falhas de outros policiais militares, caso as conheça, às instâncias competentes.

\section{Considerações finais}

Esses contextos apresentados descrevem, em alguma medida, a sensação de desrespeito e falta de reconhecimento compartilhados no meio profissional da força pública como resultados da crise da corporação militar diante de seus profissionais. Esses processos de classificação, divisão, punição e purificação, expressa o cotidiano e a história social da PMCE. Elaboram não só definições do que é a falha profissional, enquanto conjunto de práticas nesse mundo, mas concepções morais do que é o policial militar e do que é a polícia militar. É, portanto, um modo de invenção de sujeitos. 
Algo que tem sido bastante debatido na literatura sobre a polícia militar no Brasil é a distância social entre as instituições policiais e seus públicosalvos $^{9}$. Este entendimento foi usado como justificativa para a elaboração de políticas de segurança para aproximar essas instituições dos cidadãos, conforme observaram Barreira (2004) e Pinheiro (2008) no contexto cearense. Esse processo parece ter uma relação muito forte com a grave crise de legitimidade dessa entidade social, a Polícia Militar, na vida social brasileira. Há uma discussão muito importante, realizada por Muniz (2001), a respeito da dupla crise experimentada pelas polícias militares. Por um lado, essa crise diz respeito a atuação como polícia ostensiva, uma vez que sua atuação profissional se assemelha mais a uma corporação militar, do que com uma polícia ostensiva. Por outro, essa confusão acaba lançando mão de uma dificuldade de lidar com suas clientelas (BARBOSA e SÁ, 2015). Desse modo, essas duas dimensões da crise de identidade se complementam na explicação desse processo de objetivação que estou remetendo. O que muda, talvez, é questionar em que medida o militarismo é preponderante nesse processo, uma vez que esse tipo de situação ocorre em outros mundos profissionais não militarizados.

Essas relações entre superiores e subordinados apresentadas aqui

$9 \quad$ A título de curiosidade, li um relato de Howard Becker em seu livro Outsiders (BECKER, 2008) citando seu orientador Hughes, cujas pesquisas qualitativas registraram uma série de recorrências em que profissionais desenvolviam ojeriza aos seus públicos. Professores recorrentemente nas horas vagas tinham o hábito de falar mal de alunos, enquanto músicos não apreciavam os públicos que os assistiam e médicos desenvolviam aversão a pacientes. É comum presenciar experiências desse tipo em nossas vidas profissionais. Isto leva a crer que a produção da distância social entre profissionais e seus públicos não é um caso singular da força policial brasileira, contudo devemos entender que isto reflete consequências específicas para este campo profissional, pois assim como os médicos, os policiais e a instituição policial lidam mais diretamente com biopolíticas. Uma hipótese que pode ser levantada ao longo do estudo é como essa ideia de objetividade é absorvida no seio da instituição policial e é incorporada nas práticas profissionais da polícia. 
funcionam para os policiais como mapas agentivos para profissão. Isto se reforça na medida em que os relatos são compartilhados com outros colegas. Aprender os cortes interacionais e as maneiras bem sucedidas de lidar com as personalidades e temperamento de superiores e subordinados, é um processo decisivo na construção da subjetividade dos policiais militares. A produção institucional, da diferença social entre um profissional militar e outros grupos profissionais civis, é um ritual permanente da instituição, em grande parte incorporada nas práticas dos policiais militares.

Muitos policiais, ao deixarem as filas da instituição em busca de outros mundos profissionais, possuem o forte desejo de sair da instituição no curto e médio prazo, sejam praças, sejam oficiais. Esses processos revelam as marcas do sofrimento na profissão e na subjetividade dos policiais militares que, aos poucos, minam a energia corporal dos policiais, empregada na realização do seu serviço, e motivam planos de fuga. Mas essa crise não se resume apenas à essa dimensão. Há fugas desse sofrimento que se realizam para dentro: construindo capital social com os superiores, tentando o ingresso no oficialato, competindo por promoções na carreira e por outras funções que possam ser desempenhadas na instituição.

O caminho esboçado para compreender essas relações foi confrontar o militarismo como categoria nativa e como categoria de análise na problematização dessa crise e seus efeitos; como agência, como norma e como subjetivação dos policiais militares. Pode se dizer que os dados construídos pela pesquisa conduzem a um maior enfoque na percepção de policiais militares do círculo hierárquico da praça sobre essas dimensões, uma vez que, a interlocução ocorreu de maneira mais intensa e regular com esses sujeitos. As rotinas militares da profissão colocam em movimento um grande número de relações de conflito e de poder que dão contornos analíticos ao que estou chamando de crise do militarismo na PMCE. 
Não creio que a constatação dessa crise leve a um prognóstico positivo de democratização no interior da instituição para os próximos anos. Como revela o estudo de Carlos Barbosa, na história social da força pública cearense, as crises sempre foram respondidas por um recrudescimento do militarismo na instituição (BARBOSA, 2014). O militarismo não é só uma palavra, é uma instituição duradoura de diferença, que não está apenas nas normas e leis que regulamentam a profissão. Ela está inscrita nos corpos, sob a forma de memórias, pensamentos, percepções, conhecimentos e práticas de tal modo que, somente a "desmilitarização" da instituição não a conduzirá por um passe de mágica a melhoria desses processos. Essas virtudes, valorizadas na autoimagem da corporação e nas interações sociais dos corpos de policiais militares, não estão apenas no mundo institucional, mas no córpus social mais amplo, caso contrário, ela seria insustentável.

\section{REFERÊNCIAS}

BARREIRA, Cesar. Crimes por encomenda: violência e pistolagem no cenário brasileiro. Rio de Janeiro: Relume Dumará: NUAP, 1998.

BARBOSA, Wendell de Freitas. A polícia da boa vizinhança: as ações da polícia em contextos de conflito e a produção intersubjetiva de práticas policiais locais. 2014. 208 f. Dissertação (Mestrado) - Curso de Sociologia, Ciências Sociais, Universidade Federal do Ceará, Fortaleza, 2014 .

;SÁ, Leonardo de. Redefinições da condição de morado: Classificações da clientela no mandato policial e suas consequências nas relações de polícia e população. Caderno CRH, Vol. 28, no 75. 2015, pp. $639-656$.

BOLTANSKI, L.; THEVENOT, L.. The Sociology of Critical Capacity. European Journal Of Social Theory, [s.1.], v. 2, n. 3, p.359-377, 1 ago. 
1999 .

BOLTANSKI, Luc; THÉVENOT, Laurent. De la justification: Les économie de la grandeur. Paris: Gallimard, 1991.

BOURDIEU, Pierre. A distinção: Crítica social do julgamento. São Paulo; Rio Grande do Sul: Edusp; Zouk, 2007.

- Sobre o Estado: Cursos no Collège de France. São Paulo: Companhia das Letras, 2014.

BRASIL, Glaucíria Mota. As crises na segurança pública: Mudanças e Permanencias. Políticas Públicas e Sociedade, Fortaleza - Ce, v. 6, n. 1, p.89-106, jan. 2003.

BRETAS, Marcos. Ordem na cidade: $O$ exercício cotidiano da autoridade policial no Rio de Janeiro. Rio de Janeiro: Rocco, 1997.

CASTRO, Celso. O Espirito Militar: Um antropólogo na caserna. Rio: Jorge Zahar, 1997.

CHATEAURAYNAUD, Francis. La faute professionnelle. Paris: Éditions Métailié, 1991.

DIÓGENES, José Lenho Silva; BARREIRA, César. "Criminação” militar de praças e o funcionamento da PMCE. In: ENCONTRO ANUAL DA APOCS, 37, 2013, Águas de Lindóia. Anais... . Águas de Lindóia: Anpocs, 2013. p. $1-25$.

DUMONT, Louis. Homo Hierarchichus. São Paulo: Edusp, 2008.

ELIAS, Norbert. A sociedade de corte: Investigação sobre a sociologia da realeza e da aristocracia da corte. Rio de Janeiro: Jorge Zahar, 2001.

O processo Civilizador Volume II: Formação do Estado e 
Civilização. Rio de Janeiro: Jorge Zahar, 1993.

Os Alemães: A luta pelo poder e a evolução do habitus nos séculos XIX e XX. Rio de Janeiro: Jorge Zahar, 1997.

Os estabelecidos e os outsiders: sociologia das relações de poder a partir de uma pequena comunidade. Rio de Janeiro: Jorge Zahar, 2001.

FOUCAULT, Michel. História da sexualidade Volume I: A vontade de saber. Rio de Janeiro: Edições Graal, 1999.

Vigiar e Punir: Nascimento da prisão. Petrópolis: Vozes, 2012.

GARFINKEL, Harold. Estudios en Etnometodología. Barcelona: Anthropos Editorial, 2006.

GEERTZ, Clifford. O Saber local: novos ensaios em antropologia interpretativa. Petrópolis: Vozes, 1997.

GIDDENS, Anthony. O Estado-Nação e a Violência: Segundo volume de uma crítica contemporânea ao materialismo histórico. São Paulo: Edusp, 2008.

GLASER, Barney; STRAUSS, Anselm. The discovery of grounded theory: strategies for qualitative ressearch. New York: Aldine, 1967.

GOFFMAN, Erving. Manicômios, prisões e conventos. São Paulo: Perspectiva, 1974 .

Comportamentos em lugares públicos: Notas sobre a organização social dos ajuntamentos. Petrópolis: Vozes, 2010.

Ritual de interação: Ensaios sobre o comportamento face-aface. Petrópolis: Vozes, 2011. 
Estigma: Notas sobre a manipulação da identidade deteriorada. 4. ed. Rio de Janeiro: Ltc, 2012.

JOAS, Hans. Pragmatism and social theory. Chicago: The University Of Chicago Press, 1993.

. The sacradness of the person: A new genealogy of.

Washington: Georgetown University Press, 2013.

MISSE, Michel. O rio como um bazar: A conversão da ilegalidade em mercadoria política. Insight Inteligência, Rio de Janeiro, v. 5, n. 3, p.1216, 2002.

PINHEIRO, Antonio dos Santos. Polícia Comunitária e Cidadã: Entre velhas e novas práticas policiais. Crato: Rds, 2015.

POLLAK, Michel. Memoria, olvido, silencio: la produccion social de identidades frente situaciones íimite. Buenos Aires: Ediciones $\mathrm{Al}$ Margen, 2006.

RATTON, José Luiz; BARROS, Marcelo (Org.). Polícia, Democracia e Sociedade. Rio de Janeiro: Lumen Juris, 2007.

SÁ, Leonardo. Os filhos do estado: Autoimagem e disciplina na formação dos oficiais da Polícia Militar do Ceará. Rio de Janeiro: Relume-dumará, 2002.

; SALES, Larissa Jucá de Moraes; SABINO, Antonio.. Luta por reconhecimento, consideração e direitos nos movimentos paredistas da Polícia Militar do Ceará(1997-2011). In: ENCONTRO ANUAL DA ANPOCS, 39., 2015, Caxambu. Anais.... Caxambu: Anpocs, 2015. p. 1 - 21.

SACKS, Harvey. Part I Fall 1964-Spring 1965. In: SACKS, Harvey. Lectures on conversation Volumes I \& II. Cornwall : Blackwell 
Publishing, 1995 p. 3-134.

SALES, Larissa Jucá de Morais. Medo e sofrimento social: Uma narrativa de policiais militares em atendimento clínico. 2013. $127 \mathrm{f}$. Dissertação (Mestrado) - Curso de Sociologia, Ciências Sociais, Universidade Federal do Ceará, Fortaleza, 2013.

SILVA, Antonio Marcos da. A inversão da ordem na vida policial: Sociabilidade prisional e práticas ilegais. 2015. $275 \mathrm{f}$. Tese (Doutorado) - Curso de Sociologia, Universidade Federal do Ceará, Fortaleza, 2015.

Sociología: Estudios sobre las formas de socialización. Madrid: Alianza Editorial, 1977.

. The intersection of social circles. In: SIMMEL, George. Inquires into the construction of social forms. Leiden; Boston: Brill, 2009. p. $363-408$.

: Sociologia do espaço. Estudos Avançados, [s.1.], v. 27, n. 79, p.75$112,2013$.

SOUSA, Tuany Maria de. Percepções sobre adoecimento e risco no trabalho de policiais militares. 2015. 135 f. Dissertação (Mestrado) Curso de Políticas Públicas, Mapss, Universidade Estadual do Ceará, Fortaleza, 2015. Cap. 135.

WEBER, Max. Economía y sociedad: Esbozo de sociología comprensiva. Madrid: Fondo de Cultura Económica, 2002. 